\title{
Efficacy and Safety of Ixekizumab Through 5 Years in Moderate-to-Severe Psoriasis: Long-Term Results from the UNCOVER-1 and UNCOVER-2 Phase-3 Randomized Controlled Trials
}

\author{
Craig Leonardi · Kristian Reich (D) - Peter Foley (D) - Hideshi Torii · Sascha Gerdes • \\ Lyn Guenther (D) - Melinda Gooderham (D) - Laura K. Ferris (D) - Christopher E. M. Griffiths • \\ Hany ElMaraghy · Heidi Crane $\cdot$ Himanshu Patel $\cdot$ Russel Burge · Gaia Gallo • David Shrom • \\ Ann Leung $\cdot$ Chen-Yen Lin · Kim Papp (D)
}

Received: August 30, 2019 / Published online: March 21, 2020

(C) The Author(s) 2020

\section{ABSTRACT}

Introduction: Ixekizumab, a high-affinity monoclonal antibody that selectively targets interleukin-17A, is approved for treatment of moderate-to-severe plaque psoriasis. Our objective was to evaluate the long-term efficacy and safety of ixekizumab in moderate-to-severe plaque psoriasis through 5 years.

Digital Features To view enhanced digital features for this article go to https://doi.org/10.6084/m9.figshare. 11925636.

Electronic Supplementary Material The online version of this article (https://doi.org/10.1007/s13555020-00367-x) contains supplementary material, which is available to authorized users.

C. Leonardi

Central Dermatology, St. Louis, MO, USA

K. Reich

Center for Translational Research in Inflammatory

Skin Diseases, Institute for Health Services Research

in Dermatology and Nursing, University Medical

Center Hamburg-Eppendorf, Hamburg, Germany

K. Reich

Skinflammation ${ }^{\circledR}$ Center, Hamburg, Germany

P. Foley

St. Vincent's Hospital Melbourne and Probity

Medical Research, Skin Health Institute, The

University of Melbourne, Melbourne, VIC, Australia
Methods: Data were integrated from the UNCOVER-1 and UNCOVER-2, randomized, double-blinded, phase- 3 trials. Patients who continuously received the labeled ixekizumab dose, were static Physician's Global Assessment (sPGA) $(0,1)$ responders at Week 12 and completed 60 weeks of treatment could enter the long-term extension (LTE) period. Patients could escalate to every-2-week dosing per investigator opinion. Efficacy and health outcomes included proportion of patients achieving Psoriasis Area and Severity Index (PASI) $75 / 90 / 100$, sPGA $(0,1)$ and $(0)$, absolute PASI $\leq 5 / \leq 3 / \leq 2 / \leq 1$ and Dermatology Life Quality Index (DLQI) $(0,1)$. Results exclude patients who escalated to every-2-week dosing. A

H. Torii

Division of Dermatology, Tokyo Yamate Medical Center, Tokyo, Japan

\section{S. Gerdes}

Psoriasis-Center at the Department of Dermatology, University Medical Center Schleswig-Holstein, Campus Kiel, Kiel, Germany

\section{Guenther}

Guenther Dermatology Research Centre, London, ON, Canada

M. Gooderham

SkiN Centre for Dermatology and Probity Medical Research, Peterborough, ON, Canada 
modified non-responder imputation method was used to account for missing data. Supplemental analyses include patients who escalated to every-2-week dosing and observed and multiple imputation results. Exposure-adjusted safety outcomes are also reported.

Results: Of 206 patients who entered the LTE periods, 172 completed treatment. At Week 60, PASI 75/90/100 responses were 94.7\%, 85.0\% and $62.1 \%$, respectively, and at year 5 were $90.3 \%, 71.3 \%$ and $46.3 \%$, respectively. Similarly, meaningful responses were achieved for the other efficacy and health measures. Among patients with PASI 100 through 5 years, 92\% achieved DLQI $(0,1)$, indicating no impact of skin disease on quality of life. During the LTE period, exposure-adjusted incidence rates were 31.4 per 100 patient-years for treatment-emergent adverse events and 6.8 per 100 patientyears for serious adverse events. No deaths were reported. No new or unexpected safety findings were noted.

Conclusions: The results demonstrate $80 \mathrm{mg}$ ixekizumab maintains long-term efficacy and a safety profile consistent with previous data in patients with moderate-to-severe plaque psoriasis through 5 years of treatment.

Trial Registration: ClinicalTrials.gov identifier, UNCOVER-1: NCT01474512, UNCOVER-2: NCT01597245.

L. K. Ferris

University of Pittsburgh Medical Center, Pittsburgh,

PA, USA

C. E. M. Griffiths

Dermatology Centre, Salford Royal Hospital,

University of Manchester, Manchester, UK

H. ElMaraghy · H. Crane $\cdot$ H. Patel · R. Burge

G. Gallo · D. Shrom $(\bowtie) \cdot$ C.-Y. Lin

Eli Lilly and Company, Lilly Corporate Center, Indianapolis, IN, USA

e-mail: shrom_david_stanley@lilly.com

A. Leung

Syneos Health, Morrisville, NC, USA

K. Papp

K. Papp Clinical Research and Probity Medical

Research Inc., Waterloo, ON, Canada
Keywords: Ixekizumab; Long-term efficacy; Long-term safety; Maintain; Psoriasis; Quality of life; 5 years

\section{Key Summary Points}

\section{Why carry out this study?}

Plaque psoriasis is a common, chronic immunologic disorder with an estimated prevalence ranging from approximately 1.0 to $8.5 \%$ worldwide and a negative impact on quality of life.

Psoriasis is a chronic, lifelong disease, and it is therefore essential to understand the long-term efficacy and safety profile of psoriasis treatments.

In this report, we present the 5-year efficacy and safety outcomes from the long-term extension periods of the UNCOVER-1 and UNCOVER-2 studies, phase- 3 randomized-controlled trials in patients with moderate-to-severe psoriasis treated with the labeled dose of ixekizumab.

\section{What was learned from this study?}

Ixekizumab therapy provided long-lasting efficacy in patients with psoriasis over 5 years of treatment.

No unexpected safety signals were reported with long-term exposure to ixekizumab in this study.

$100 \%$ improvement in psoriasis severity (Psoriasis Area and Severity Index 100) was strongly associated with good patientreported quality of life (Dermatology Life Quality Index 0,1) through 5 years, showing clear skin over long periods is the optimal treatment outcome for patients with psoriasis. 


\section{INTRODUCTION}

Plaque psoriasis is a common, chronic immunologic disorder with an estimated prevalence ranging from approximately $1.0-8.5 \%$ worldwide $[1,2]$. Psoriasis is associated with important comorbidities, including psoriatic arthritis, diabetes, cardiovascular disease and depression $[3,4]$. Together with physical discomfort, the various signs and symptoms of psoriasis have a significant impact on social relationships, mental health and work-related activities, leading to poor quality of life (QoL) [3-6].

Biologic therapies targeting immune-related, proinflammatory cytokine pathways have fulfilled long unmet clinical needs in the treatment of moderate-to-severe psoriasis [7]. Firstgeneration biologics, which target tumor necrosis factor alpha (TNF $\alpha)[8]$, have produced favorable responses in subjects with psoriasis [9-11]. Though TNF $\alpha$ inhibitors are efficacious in psoriasis [12], many patients continue to experience suboptimal levels of clearance and adverse effects while taking these agents [12]. Recently, cytokine inhibitors targeting key inflammatory molecules, like the interleukin (IL)-23/IL-17 pathways, instead of generalized immunosuppression, have shown efficacy in psoriasis patients in randomized studies, including the IL-23 inhibitors ustekinumab (anti-IL-12/IL-23) [13-15], guselkumab [16, 17], risankizumab [18] and tildrakizumab [19] and the IL-17 inhibitors secukinumab [20], brodalumab [21, 22] and ixekizumab [23-25].

Because psoriasis is chronic, it requires longterm management. Substantial evidence has accumulated supporting the meaningful benefits of clearer skin and a significant negative effect of residual psoriatic lesions on QoL among patients with moderate-to-severe disease [26-31]. Therefore, it is essential to understand the long-term efficacy and safety profile of psoriasis treatments, especially the ability to provide clear skin over long periods. However, these types of studies are not common, with only secukinumab and ustekinumab providing efficacy and safety data in moderate-to-severe psoriasis up to 5 years $[13,14,32]$.
Ixekizumab is an immunoglobulin $G$ subclass 4 monoclonal antibody that selectively targets and binds IL-17A with high specificity and affinity, blocks the binding of IL-17A to the IL-17A receptor and neutralizes IL-17A activity [33]. IL-17A is increased in the psoriatic lesions of patients with psoriasis [34, 35]. Neutralizing IL-17A decreases immune system activity and decreases inflammation, resulting in reversal of psoriasis symptoms [36]. Ixekizumab is approved for use in patients with moderate-tosevere plaque psoriasis based on efficacy and safety established in phase-3 randomized, clinical trials [23-25] and has a rapid onset of action with reported efficacy sustained over 4 years $[37,38]$.

In this report, we present the 5-year efficacy and safety outcomes from the long-term extension periods of the UNCOVER-1 and UNCOVER-2 studies, two phase-3, randomizedcontrolled trials in patients with moderate-tosevere psoriasis who received the approved dosing regimen of ixekizumab.

\section{METHODS}

\section{Study Design}

The UNCOVER-1 (ClinicalTrials.gov registration no. NCT01474512) and UNCOVER-2 (ClinicalTrials.gov registration no. NCT01597245) studies were multicenter, randomized, double-blinded, placebo-controlled, phase-3 clinical trials; UNCOVER-1 was conducted at 109 study sites in 11 countries and UNCOVER-2 was conducted at 127 study sites in 12 countries. Both trials have been described in detail previously [23]. UNCOVER-2 also used an active comparator (etanercept) [23]. Briefly, patients were randomized to placebo, $80 \mathrm{mg}$ of ixekizumab every 2 weeks or every 4 weeks, or $50 \mathrm{mg}$ etanercept twice weekly (in UNCOVER-2) for 12 weeks (induction period) [Electronic Supplemental Material (ESM) Fig. S1]. Patients assigned to an ixekizumab regimen received a 160 -mg starting dose. At week 12, static Physician's Global Assessment (sPGA) $(0,1)$ responders (sPGA score of 0 or 1 ) randomized to an ixekizumab arm at Week 0 were then 


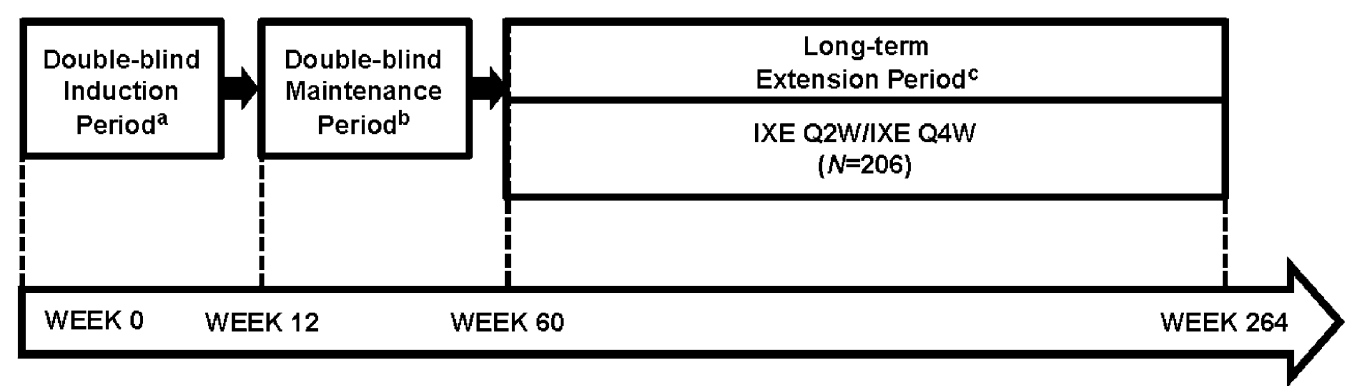

Fig. 1 UNCOVER-1 and UNCOVER-2 Study Design: Approved dosing regimen patient population. IXE Q2W ixekizumab every 2 weeks; $I X E Q 4 W$ ixekizumab every 4 weeks. ${ }^{\text {a}}$ Week 0: patients randomized to $80 \mathrm{mg}$ IXE Q2W, $80 \mathrm{mg}$ IXE Q4W or placebo. ${ }^{\text {bWeek 12: Static }}$ Physician's Global Assessment (sPGA) (0,1) responders

randomized to ixekizumab every 4 weeks, ixekizumab every 12 weeks or placebo from week 12 to week 60 (maintenance dosing period). Nonresponders receiving ixekizumab every 4 weeks remained on that regimen, and non-responders receiving ixekizumab every 2 weeks, placebo or etanercept (UNCOVER-2) switched to the ixekizumab every-4-week regimen. At week 60, patients could enter the long-term extension period. The long-term extension period was blinded until all patients reached week 60 or discontinued, after which the study became open label. For all patients treated for at least 12 weeks with $80 \mathrm{mg}$ ixekizumab every 4 weeks and who completed 60 weeks of treatment, a dose increase to $80 \mathrm{mg}$ ixekizumab every 2 weeks (off label) was allowed during the longterm extension period if it was deemed appropriate by the patient and the investigator.

Here, we report efficacy and safety results for patients who continued into the long-term extension periods of UNCOVER-1 and UNCOVER-2 through 5 years (week 60-week 264) after completing the induction and randomized maintenance periods (Fig. 1). This report focuses on data from patients who received the approved regimen (an initial dose of $160 \mathrm{mg}, 80 \mathrm{mg}$ ixekizumab every 2 weeks up through week 12 and $80 \mathrm{mg}$ ixekizumab every 4 weeks thereafter). Data including both every4-week dosing and patients who escalated to every-2-week dosing during the long-term extension period are included in electronic randomized to $80 \mathrm{mg}$ IXE Q4W, $80 \mathrm{mg}$ IXE Q12W (every 12 weeks) or placebo. ${ }^{c}$ From Weeks 60 to 264 , patients and investigators could elect to escalate to $80 \mathrm{mg}$ IXE Q2W dosing through end of study to achieve or maintain efficacy

supplemental materials (ESM Table S1 and Fig. S2).

Patients included in the studies were male or female, aged $\geq 18$ years, had a confirmed diagnosis of chronic plaque psoriasis for at least 6 months, were candidates for phototherapy and/or systemic therapy, and had $\geq 10 \%$ body surface area (BSA) involvement, an sPGA score of $\geq 3$, and a Psoriasis Area and Severity Index (PASI) score of $\geq 12$ at screening and at baseline. Patients were excluded from the studies if they had pustular, erythrodermic and/or guttate forms of psoriasis; a history of drug-induced psoriasis; a clinically significant flare of psoriasis during the 12 weeks before baseline; or used systemic nonbiologic psoriasis therapy, topical psoriasis treatment or biologic agents within the washout periods. Patients were excluded from UNCOVER-2 if they had used etanercept prior to the study.

\section{Study Objectives}

The objective of this integrated analysis was to evaluate the long-term efficacy, health outcomes and safety of treatment with ixekizumab with the approved dosing regimen through 5 years. Efficacy assessments included PASI 75/90/100, sPGA $(0,1)$ and sPGA $(0)$, absolute PASI $\leq 5 / \leq 3 / \leq 2 / \leq 1$ and Dermatology Life Quality Index (DLQI) $(0,1)$ responses. Safety assessments included adverse events (AEs), AEs 
of special interest, serious AEs and discontinuations due to AEs.

\section{Compliance with Ethics Guidelines}

The ethics review boards at each study site provided written approval of the study protocol and an informed consent form. The Central Ethics Committee for the UNCOVER-1 and UNCOVER-2 studies in the country of the coordinating investigators (US) was the Schulman Associates IRB in Ohio, USA. A list of the ethics committees for countries and study sites for UNCOVER-1 and UNCOVER-2 is presented in ESM Table S3. All procedures performed in studies involving human participants were in accordance with the ethical standards of the institutional and/or national research committee and with the 1964 Helsinki Declaration and its later amendments or comparable ethical standards. Informed consent was obtained from all individual participants included in the study.

\section{Statistical Methods}

Efficacy and safety outcomes were evaluated for patients who received the approved dosing regimen (an initial dose of $160 \mathrm{mg}, 80 \mathrm{mg}$ ixekizumab every 2 weeks up through Week 12 and $80 \mathrm{mg}$ ixekizumab every 4 weeks thereafter) and entered in the long-term extension period (i.e., approved dosing regimen population). Data including both every-4-week dosing and patients who escalated to every-2-week dosing during the long-term extension period are included in the ESM (Fig. S2 and Table S1 of the ESM). The PASI combines assessments of the extent of body surface involvement in four anatomical regions and the severity of desquamation (scaling), erythema (redness) and plaque induration/infiltration (thickness) in each region, yielding an overall score of 0 for no psoriasis to 72 for the most severe disease, as previously described [39]. PASI 75, PASI 90 and PASI 100 responses are defined as having improvement from baseline in PASI scores of $\geq$ $75 \%, \geq 90 \%$ and $100 \%$, respectively. The sPGA is the physician's assessment of the patient's psoriasis lesions overall at a given point in time. An sPGA $(0,1)$ response is defined as a postbaseline sPGA score of 0 (clear) or 1 (minimal). An sPGA (0) response is defined as a post-baseline sPGA score of 0 (i.e., clear). A DLQI $(0,1)$ response is defined as a post-baseline DLQI score of 0 or 1 (no effect on patient's life) [40].

Patients who received the approved dosing regimen (an initial dose of $160 \mathrm{mg}, 80 \mathrm{mg}$ ixekizumab every 2 weeks up through Week 12 and $80 \mathrm{mg}$ ixekizumab every 4 weeks thereafter) were analyzed. Efficacy analyses were performed excluding data from patients who escalated to dosing every 2 weeks in the primary analysis presented here. Efficacy analyses performed including the data from patients who escalated to dosing every 2 weeks are included in the ESM (Fig. S2 and Table S1 of the ESM). Modified nonresponder imputation results are presented for the efficacy and patient reported outcome response assessments, as was done previously $[41,42]$, as modified nonresponder imputation analysis is a relatively conservative method. Study outcomes were also evaluated according to the observed case and using multiple imputation (presented in ESM Fig. S3), as was done previously [41, 42]. The observed case method did not require imputation for missing values, as only data from patients who remained in the study were analyzed. The multiple imputation method was used to estimate what observed values would have been if the patient had continued, based on a hypothetical strategy, as previously described [43]. The modified nonresponder imputation method analyzed patient response status using a composite strategy [43]: missing data due to study drug-related events (e.g., inadequate response, AEs, lack of efficacy) were considered as non-responders and were imputed using nonresponder imputation. Alternatively, missing data due to reasons unrelated to the study drug were imputed using multiple imputation, as described above.

Safety events in the approved dosing regimen patient population were summarized by exposure-adjusted incidence rate (IR) (i.e., person-time-adjusted incidence rate per 100 patient-years). Safety events in the approved dosing regimen patient population were summarized both for the entire study and the long- 
term extension period overall. The statistical analyses of efficacy, health outcomes and safety measures were performed using $\mathrm{SAS}{ }^{\circledR}$ version 9.2 (SAS Institute, Cary, NC, USA).

\section{RESULTS}

\section{Baseline Characteristics and Patient Disposition}

Demographic and baseline characteristics of patients in the approved dosing regimen patient population are presented in Table 1 . High disease severity at baseline is indicated by a mean PASI of 19.3, mean sPGA of 3.5 , mean BSA involvement of $27.1 \%$ and mean DLQI of 12.1. The PASI, sPGA and BSA data are consistent with the overall population randomized at baseline of the study [23]. Other baseline characteristics are also mostly consistent between the approved dosing regimen patient population and the overall population, including sex, age and previous treatment.

Of the 206 patients who entered the longterm extension period in the two studies, 172 completed the studies (Table 2 and ESM Fig. S1). Reasons for discontinuation during the longterm extension period included $\mathrm{AE}$, patient decision, investigator decision, lack of efficacy, lost to follow-up, clinical relapse, parent/caregiver decision and protocol violation (Table 2). A total of 43 patients escalated to dosing every 2 weeks during the long-term extension period (ESM Table S1).

\section{Efficacy Outcomes Over 5 Years of Treatment}

The PASI 75/90/100 responses were 94.7\%, $85.0 \%$ and $62.1 \%$, respectively, at Week 60 , and at Year 5 (Week 264) were 90.3\%, 71.3\% and $46.3 \%$, respectively (Fig. 2a). Responses were consistent when the data were analyzed according to the observed case or using multiple imputation (ESM Fig. S3a). Similarly, meaningful responses were seen with sPGA $(0,1)$ and sPGA (0) (Fig. 2b and ESM Fig. S3b).
Table 1 Demographics and baseline characteristics of patients entering the long-term extension period (approved dosing regimen patient population)

\begin{tabular}{|c|c|}
\hline Characteristics & $\begin{array}{l}\text { IXE Q2W/IXE } \\
\text { Q4W } \\
80 \mathrm{mg} \\
(N=206)\end{array}$ \\
\hline \multicolumn{2}{|l|}{ Sex, $n(\%)$} \\
\hline Male & $140(68.0)$ \\
\hline Age (years), median (range) & $43.0(18-77)$ \\
\hline \multicolumn{2}{|l|}{ Race, $n(\%)$} \\
\hline Caucasian & $193(93.7)$ \\
\hline Asian & $8(3.9)$ \\
\hline Black or African American & $3(1.5)$ \\
\hline Multiple & $2(1.0)$ \\
\hline \multicolumn{2}{|l|}{ Geographic region, $n(\%)$} \\
\hline North America & $102(49.5)$ \\
\hline USA & $59(28.6)$ \\
\hline Europe & $95(46.1)$ \\
\hline Asia & $3(1.5)$ \\
\hline Australia & $6(2.9)$ \\
\hline Height $(\mathrm{cm})$, median (range) & $\begin{array}{l}173.15 \\
\quad(146.0-196.0)\end{array}$ \\
\hline Weight $(\mathrm{kg})$, median (range) & $\begin{array}{l}88.25 \\
\quad(50.0-160.0)\end{array}$ \\
\hline BMI $\left(\mathrm{kg} / \mathrm{m}^{2}\right)$, median (range) & $\begin{array}{l}29.25 \\
\quad(17.5-55.3)\end{array}$ \\
\hline Tobacco use, $n(\%)$ & $69(33.5)$ \\
\hline Alcohol consumption, $n$ (\%) & $122(59.2)$ \\
\hline $\begin{array}{l}\text { Duration of psoriasis symptoms } \\
\text { (years), mean }(\mathrm{SD})^{\mathrm{a}}\end{array}$ & $18.6(12.3)$ \\
\hline $\begin{array}{l}\text { Age of psoriasis onset (years), mean } \\
\text { (SD) }\end{array}$ & $25.4(12.5)$ \\
\hline \multicolumn{2}{|c|}{ Baseline efficacy/patient-reported outcome scores } \\
\hline PASI, mean (SD) & $19.3(6.9)$ \\
\hline sPGA, mean (SD) & $3.5(0.6)$ \\
\hline DLQI, mean (SD) & $12.1(6.9)$ \\
\hline
\end{tabular}


Table 1 continued

\begin{tabular}{ll}
\hline Characteristics & IXE Q2W/IXE \\
& Q4W \\
& $\mathbf{8 0 ~ m g}$ \\
& $(N=206)$
\end{tabular}

BSA involvement (\%), mean $27.1(16.2)$

(SD)

$$
\text { PsA present, } n \text { (\%) }
$$

Previous systemic therapy, $n$ (\%)

$\begin{array}{ll}\text { Never used } & 65(31.6) \\ \text { Non-biologic only }^{\mathrm{b}} & 72(35.0) \\ \text { Biologic only } & 16(7.8) \\ \text { Biologic and non-biologic } & 53(25.7) \\ \text { Previous biologic therapy, } n(\%) & 69(33.5) \\ \text { Previous phototherapy, } n(\%) & 93(45.1) \\ \text { Previous non-biologic systemic therapy, } n(\%) \\ \text { Never used } & 81(39.3) \\ \text { Used 1 therapy } & 60(29.1) \\ \text { Used } 2 \text { therapies } & 36(17.5) \\ \text { Used } \geq 3 \text { therapies } & 29(14.1)\end{array}$

Previous non-biologic systemic therapy: inadequate response, intolerance or contraindication, $n$ (\%)
Used $<3$ therapies
$185(89.8)$
Used $\geq 3$ therapies
$21(10.2)$

$B M I$ body mass index, BSA body surface area, $D L Q I$ Dermatology Life Quality Index, IXE Q2W ixekizumab every 2 weeks, IXE $Q 4 W$ ixekizumab every 4 weeks, $N$ number of patients in the analysis population, $n$ number of patients in the specified category, PASI Psoriasis Area and Severity Index, $P_{S} A$ psoriatic arthritis, $S D$ standard deviation, $s P G A$ static Physician Global Assessment, USA United States of America

${ }^{a}$ Duration of psoriasis symptoms is calculated as: date of informed consent-date of onset of psoriasis symptoms/ 365.25

b Previous non-biologic systemic therapy included methotrexate, cyclosporine, retinoids and PUVA (psoralen plus ultraviolet A radiation)
Table 2 Patient disposition, long-term extension period (approved dosing regimen patient population)

\begin{tabular}{ll}
\hline Disposition status & IXE Q2W/IXE Q4W \\
& $\mathbf{8 0 ~ m g}$ \\
& $(N=206)$ \\
\hline
\end{tabular}

Number of patients (\%)

Completed $172(83.5)$

Discontinued $34(16.5)$

Reasons for discontinuation, $n$ (\%)

$\begin{array}{ll}\text { Adverse event } & 7(3.4) \\ \text { Related to study drug } & 0 \\ \text { Patient decision } & 12(5.8) \\ \text { Investigator decision } & 5(2.4) \\ \text { Lack of efficacy } & 3(1.5) \\ \text { Lost to follow-up } & 4(1.9) \\ \text { Clinical relapse } & 1(0.5) \\ \text { Parent/caregiver decision } & 1(0.5) \\ \text { Protocol violation } & 1(0.5)\end{array}$

IXE Q2W ixekizumab every 2 weeks, IXE $Q 4 W$ ixekizumab every 4 weeks, $N$ number of patients in the analysis population, $n$ number of patients in the specified category ${ }^{a}$ Patients were allowed to escalate to IXE Q2W dosing after Week 60 during the long-term extension period. Patients who increased dosing to $80 \mathrm{mg}$ IXE Q2W remained on this dose until they completed or discontinued from the study. These data comprise all patients in the approved dosing regimen patient population, including those who escalated to every-2-week dosing during the long-term extension period

Treatment responses over time were also analyzed for absolute PASI disease severity targets. The proportions of patients with absolute PASI $\leq 5 / \leq 3 / \leq 2 / \leq 1$ were $94.7 \%, 91.3 \%$, $87.9 \%$ and $76.7 \%$, respectively, at Week 60 , and at Year 5 were $88.0 \%, 84.8 \%, 73.6 \%$ and $66.4 \%$, respectively (Fig. 2c). Responses were consistent across the observed case and multiple imputation analyses (ESM Fig. S3c).

Similar maintenance of efficacy was seen when BSA responses were analyzed (ESM Fig. S4). 

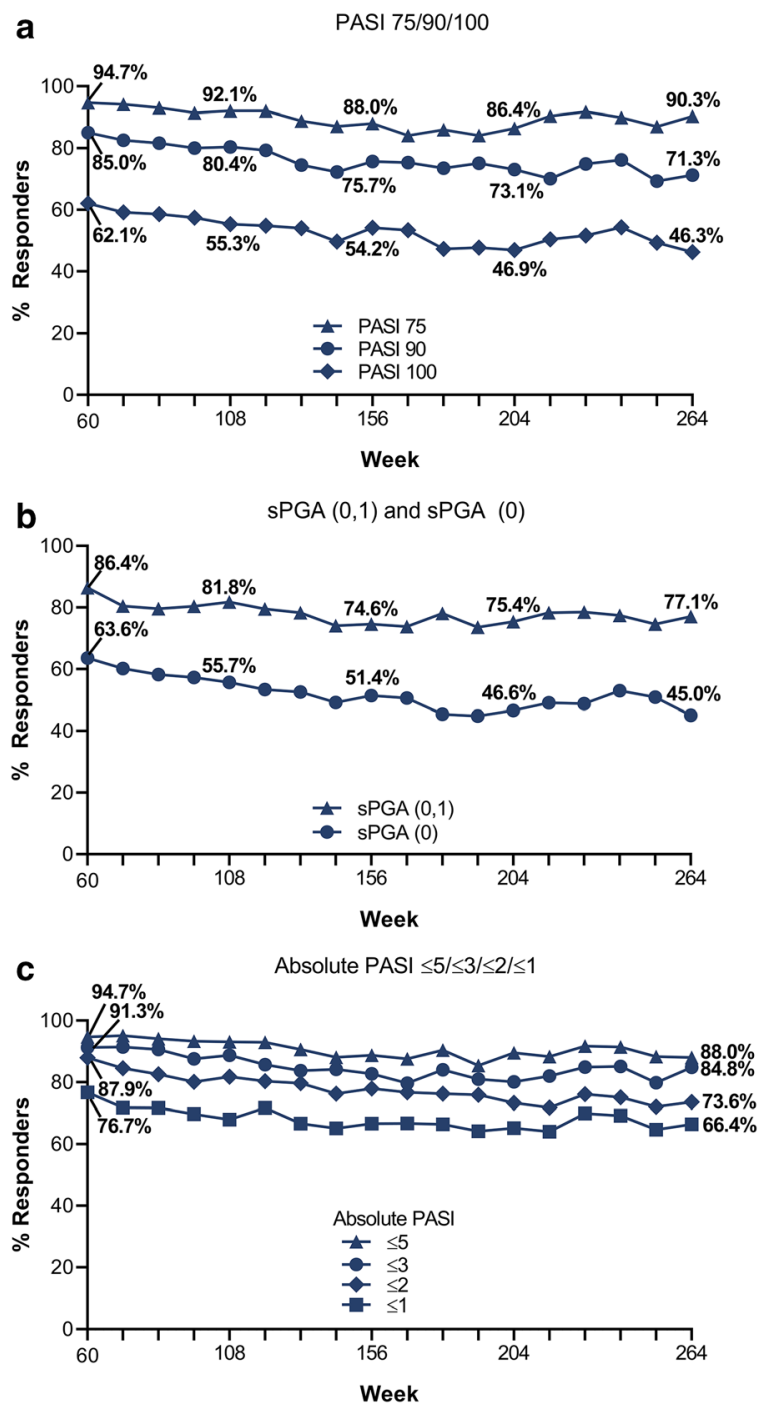

Fig. 2 Responses (modified nonresponder imputation analysis) of patients receiving $80 \mathrm{mg}$ ixekizumab every 4 weeks achieving: a Psoriasis Area and Severity Index (PASI) 75/90/100; b Static Physician's Global Assessment (sPGA) score of 0 or 1 and sPGA score of 0 ; c absolute PASI $\leq 5 / \leq 3 / \leq 2 / \leq 1$ for efficacy outcomes through 5 years of treatment. Data exclude patients who escalated to every-2-week dosing during the long-term extension period. Percentages listed on graphs are the percentage of patients achieving response at the indicated weeks of study. Each consecutive tick mark after Week 60 on the $x$ axis represents 12 weeks

The clinical response was also consistent regardless of whether visits with escalated dosing were included in the analyses (Fig. 2 versus ESM Fig. S2a-c).

\section{Patient-Reported Outcome: Dermatology Life Quality Index over 5 Years of Treatment}

Consistent with improvements in disease severity, the DLQI $(0,1)$ responses were $81.6 \%$ at Week 60 and $75.1 \%$ at Year 5 (Fig. 3). Responses were consistent across the observed case and multiple imputation analyses (ESM Fig. S3d) as well as when every-2-week dosing visits were included (ESM Fig. S2d). Patient QoL was also summarized for PASI improvement categories PASI < 90, PASI 90 to $<100$ and PASI 100. Among patients with PASI 100 at Week 60 (Year 1) and Week 264 (Year 5), approximately $90 \%$ had DLQI $(0,1)$ (Fig. 4).

\section{Safety Profile}

Safety profiles of the primary study populations in UNCOVER-1 and UNCOVER-2 through 60 weeks of treatment with ixekizumab have been previously published [23, 24]. A yearly overview of AEs from Year 1 to Year 5, as well as AEs during the long-term extension period in the approved dosing regimen patient population, is presented in Table 3. Treatment-emergent adverse events (TEAEs) occurred in 190 patients [IR (per 100 patient years): 31.4 ] during the long-term extension period. Most events reported were mild or moderate in severity, and the most frequently reported TEAEs were nasopharyngitis and upper respiratory tract infection. Forty-one patients (IR: 6.8) reported SAEs during the long-term extension period (ESM Table S2). The most frequently reported SAEs were infections (14 patients; IR: 2.3) (ESM Table S2). The IR for SAEs was lower during Year 1 (2.4), but remained consistent for Year 2 through Year 5 (7.2-9.7), and no deaths were reported. Seven patients (IR: 1.2) discontinued from the study drug because of an $\mathrm{AE}$ over the entire long-term extension period.

With respect to AEs of special interest reported during the long-term extension period, infection was the most frequently reported (150 patients, IR: 24.8). Twenty-three patients in the approved dosing regimen patient population reported Candida events across the entire study 


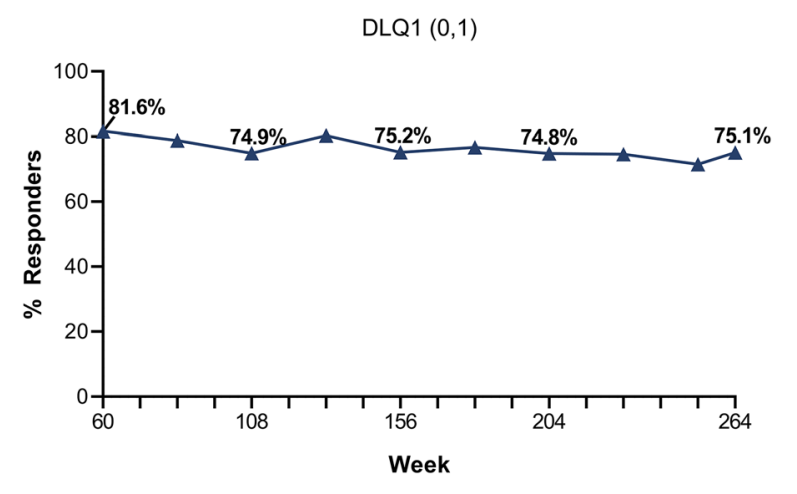

Fig. 3 Responses (modified nonresponder imputation analysis) of patients receiving $80 \mathrm{mg}$ ixekizumab every 4 weeks achieving Dermatology Life Quality Index (DLQI) scores of 0 or 1 in the long-term extension period through 5 years of treatment. Data exclude patients who escalated to every-2-week dosing during the long-term extension period. Percentages listed on the graph are the percentages of patients achieving response at the indicated weeks of study. Each consecutive tick mark after Week 60 on the $x$ axis represents 12 weeks

(candidiasis [1], esophageal [2], vaginal/genital [8], oral [10], oropharyngeal [1], pharyngeal [1], skin-related [4], thrush [1]), most of which were considered mild or moderate, with the exception of one severe case of oral Candida. Most reported Candida events were considered nonserious; one met criteria for serious designation (esophageal). Most patients reporting Candida events completed the long-term extension period; two patients discontinued study treatment, one because of investigator decision and the other because of lack of efficacy. Fifteen patients reported herpes in this population during the study (eight herpes zoster, seven herpes simplex), all of which were considered mild or moderate in severity with the exception of one severe case of herpes zoster. This case of herpes zoster also met the criteria for the serious designation (ESM Table 2). Most patients reporting herpes events completed the long-term extension period; three patients discontinued study treatment, one because of an adverse event of venous thrombosis of the limb, one because of lack of efficacy and one because of subject decision. No cases of disseminated or ophthalmic herpes zoster were reported. Four patients reported mild, non-serious events of

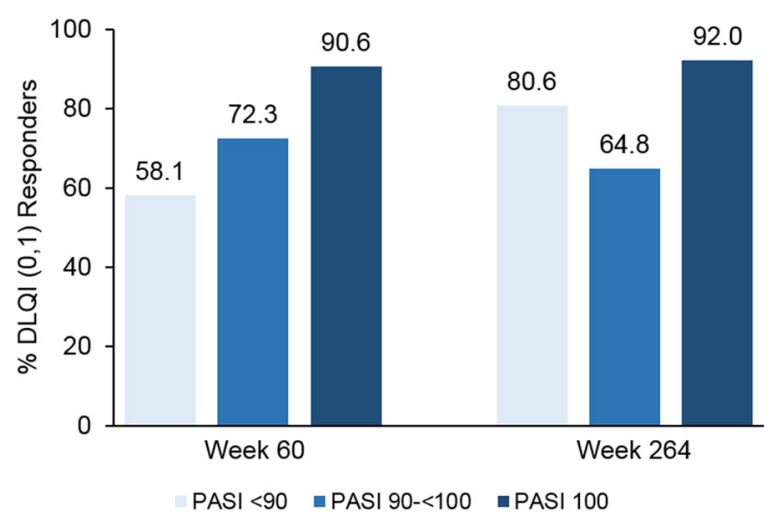

Fig. 4 Dermatology Life Quality Index (DLQI) score of 0 or $1(0,1)$ response to $80 \mathrm{mg}$ ixekizumab every 4 weeks by Psoriasis Area and Severity Index (PASI) percent improvement group (observed) at Week 60 (Year 1) and Week 264 (Year 5) in the approved dosing regimen patient population. Data exclude patients who escalated to every-2-week dosing during the long-term extension period. Numbers above each bar in the graph are the percentage of DLQI $(0,1)$ responders in the indicated PASI percent improvement group

latent tuberculosis and Mycobacterium tuberculosis complex test-positive results prior to study treatment and received treatment with isoniazid (for latent tuberculosis or as prophylaxis) to be eligible for the study. All four patients completed the long-term extension period. One patient reported Mycobacterium tuberculosis complex test-positive results (non-serious, of moderate severity) during the long-term extension period. This patient had no history of tuberculosis, was treated with isoniazid and completed the long-term extension period. No cases of reactivated tuberculosis were reported. Overall, 22 patients (IR: 3.6) experienced at least one opportunistic infection event during the long-term extension period. The IR of hypersensitivities was 11.7 during Year 1 and decreased to 3.3 during Year 5. No confirmed cases of anaphylaxis were reported during the long-term extension period. The overall IR of injection-site reactions was low (12 patients, IR: $2.0)$ over the entire long-term extension period; the IR was 22.9 at Year 1 and decreased to 6.1 in Year 2, 1.8 in Year 3, 2.2 in Year 4 and 0.8 in Year 5. Cerebro-cardiovascular events and depression were reported by six patients (IR: 
Table 3 Overview of adverse events (approved dosing regimen patient population)

\begin{tabular}{|c|c|c|c|c|c|c|}
\hline \multirow[t]{2}{*}{ Parameter } & \multicolumn{6}{|c|}{$\begin{array}{l}\text { IXE Q2W/IXE Q4W } \\
80 \mathrm{mg}\end{array}$} \\
\hline & $\begin{array}{l}\text { Year } 1 \\
205.1 \text { Total } \\
\text { PYb } \\
n(\text { IR) }\end{array}$ & $\begin{array}{l}\text { Year } 2 \\
195.4 \text { Total } \\
\text { PYb } \\
n \text { (IR) }\end{array}$ & $\begin{array}{l}\text { Year } 3 \\
165.6 \text { Total } \\
\text { PY }^{\mathrm{b}} \\
n(\mathrm{IR})\end{array}$ & $\begin{array}{l}\text { Year } 4 \\
136.4 \text { Total } \\
\text { PYb } \\
n(I R)\end{array}$ & $\begin{array}{l}\text { Year } 5 \\
119.5 \text { Total } \\
\text { PYb } \\
n(\text { IR) }\end{array}$ & $\begin{array}{l}\text { LTE Period } \\
604.3 \text { Total } \\
\text { PY }^{\text {b }} \\
n \text { (IR) }\end{array}$ \\
\hline Any TEAE(s) & $183(89.2)$ & $139(71.1)$ & $133(80.3)$ & $116(85.1)$ & $103(86.2)$ & $190(31.4)$ \\
\hline SAEs & $5(2.4)$ & $19(9.7)$ & $12(7.2)$ & $12(8.8)$ & $11(9.2)$ & $41(6.8)$ \\
\hline Deaths & 0 & 0 & 0 & 0 & 0 & 0 \\
\hline Discontinued due to AEs & 0 & $1(0.5)$ & $3(1.8)$ & $3(2.2)$ & 0 & $7(1.2)$ \\
\hline \multicolumn{7}{|l|}{ Most frequent TEAEs } \\
\hline Nasopharyngitis & $43(21.0)$ & $26(13.3)$ & $25(15.1)$ & $21(15.4)$ & $21(17.6)$ & $61(10.1)$ \\
\hline $\begin{array}{l}\text { Upper respiratory tract } \\
\text { infection }\end{array}$ & $31(15.1)$ & $19(9.7)$ & $14(8.5)$ & $13(9.5)$ & $6(5.0)$ & $37(6.1)$ \\
\hline \multicolumn{7}{|l|}{ TEAE severity } \\
\hline Mild & $80(39.0)$ & $62(31.7)$ & $55(33.2)$ & $47(34.5)$ & $38(31.8)$ & $48(7.9)$ \\
\hline Moderate & $90(43.9)$ & $63(32.2)$ & $64(38.6)$ & $59(43.3)$ & $49(41.0)$ & $102(16.9)$ \\
\hline Severe & $13(6.3)$ & $14(7.2)$ & $14(8.5)$ & $10(7.3)$ & $16(13.4)$ & $40(6.6)$ \\
\hline \multicolumn{7}{|l|}{ AESIs } \\
\hline Infection & $139(67.8)$ & $87(44.5)$ & $78(47.1)$ & $67(49.1)$ & $64(53.5)$ & $150(24.8)$ \\
\hline \multicolumn{7}{|c|}{ Allergic reactions/hypersensitivities } \\
\hline Non-anaphylaxis & $24(11.7)$ & $11(5.6)$ & $8(4.8)$ & $9(6.6)$ & $4(3.3)$ & $28(4.6)$ \\
\hline Anaphylaxis & 0 & 0 & 0 & 0 & 0 & 0 \\
\hline Hepatic & $12(5.9)$ & $4(2.0)$ & $5(3.0)$ & $4(2.9)$ & $4(3.3)$ & $14(2.3)$ \\
\hline Cytopenias & $5(2.4)$ & $4(2.0)$ & $4(2.4)$ & $3(2.2)$ & $4(3.3)$ & $11(1.8)$ \\
\hline Injection-site reactions & $47(22.9)$ & $12(6.1)$ & $3(1.8)$ & $3(2.2)$ & $1(0.8)$ & $12(2.0)$ \\
\hline $\begin{array}{l}\text { Cerebro-cardiovascular } \\
\text { events }\end{array}$ & 0 & $1(0.5)$ & $3(1.8)$ & $2(1.5)$ & 0 & $6(1.0)$ \\
\hline Depression & 0 & $2(1.0)$ & $4(2.4)$ & $3(2.2)$ & $1(0.8)$ & $9(1.5)$ \\
\hline Malignancies & $1(0.5)$ & $1(0.5)$ & 0 & $2(1.5)$ & 0 & $3(0.5)$ \\
\hline Crohn's disease & 0 & $1(0.5)$ & 0 & 0 & 0 & 0 \\
\hline Pneumocystis pneumonia & 0 & 0 & 0 & 0 & 0 & 0 \\
\hline Interstitial lung disease & 0 & 0 & 0 & 0 & 0 & 0 \\
\hline
\end{tabular}


Table 3 continued

\begin{tabular}{|c|c|c|c|c|c|c|}
\hline \multirow[t]{2}{*}{ Parameter } & \multicolumn{6}{|c|}{$\begin{array}{l}\text { IXE Q2W/IXE Q4W } \\
80 \mathrm{mg}\end{array}$} \\
\hline & $\begin{array}{l}\text { Year } 1 \\
205.1 \text { Total } \\
\text { PYb }^{\mathbf{b}} \\
n(\text { IR) }\end{array}$ & $\begin{array}{l}\text { Year } 2 \\
195.4 \text { Total } \\
\text { PY }^{\text {b }} \\
n(\text { IR) }\end{array}$ & $\begin{array}{l}\text { Year } 3 \\
165.6 \text { Total } \\
\text { PY } \\
n(\text { IR) }\end{array}$ & $\begin{array}{l}\text { Year } 4 \\
136.4 \text { Total } \\
\text { PY }^{\mathbf{b}} \\
n(\mathrm{IR})\end{array}$ & $\begin{array}{l}\text { Year } 5 \\
119.5 \text { Total } \\
\text { PY }^{\mathrm{b}} \\
n(\text { IR) }\end{array}$ & $\begin{array}{l}\text { LTE Period } \\
604.3 \text { Total } \\
\text { PY }^{\mathrm{b}} \\
n(\mathrm{IR})\end{array}$ \\
\hline Ulcerative colitis & 0 & 0 & 0 & 0 & 0 & 0 \\
\hline \multicolumn{7}{|c|}{$\begin{array}{l}A E \text { adverse event, } A E S I \text { adverse event of special interest, } I R \text { incidence rate per } 100 \text { patient years, } I X E Q 2 W \text { ixekizumab every } \\
2 \text { weeks, } I X E Q 4 W \text { ixekizumab every } 4 \text { weeks, } n \text { number of patients in the specified category, } P Y \text { patient years, } S A E \text { serious } \\
\text { adverse event, TEAE treatment-emergent adverse event } \\
\text { a Patients were allowed to escalate to } \mathrm{Q} 2 \mathrm{~W} \text { dosing after Week } 60 \text { during the long-term extension period. Patients who } \\
\text { increased dosing to } 80 \mathrm{mg} I X E \mathrm{Q} 2 \mathrm{~W} \text { remained on this dose until they completed or discontinued from the study. These } \\
\text { data comprise all patients in the approved dosing regimen patient population, including those who escalated to every-2-week } \\
\text { dosing during the long-term extension period. Adverse events related to discontinuation were arthralgia, ischemic stroke, } \\
\text { laryngeal squamous cell carcinoma, maternal exposure during pregnancy, prostate cancer, necrotizing fasciitis and venous } \\
\text { thrombosis of the limb }\end{array}$} \\
\hline
\end{tabular}

1.0) and nine patients (IR: 1.5), respectively. Three malignancies were reported in the population (IR: 0.5) (Bowen's disease, laryngeal squamous cell carcinoma, prostate cancer). One suspected inflammatory bowel disease event (Crohn's disease) was reported as anal fistula during Year 2 (maintenance dosing period) (IR: 0.5 ) and was adjudicated as not consistent with inflammatory bowel disease because of lack of evidence.

\section{DISCUSSION}

Long-lasting improvement in disease is an important treatment goal for both clinicians and patients $[44,45]$, and long-term data from clinical trials provide valuable information to clinicians on benefit-risk profiles. In previously reported findings, ixekizumab was well tolerated and provided a persistent and long-term clinical response through 4 years of treatment in patients with moderate-to-severe plaque psoriasis [37]. The present report confirms and extends these findings.

In patients who received the approved dosing regimen of ixekizumab through 5 years, high PASI 75, PASI 90 and PASI 100 responses were observed and remained high through the end of the long-term extension period, with
$46.3 \%$ of patients having clear skin (i.e., PASI 100 ) at Year 5 (Fig. 2a). Similar results were seen with other response metrics [i.e., sPGA (0) or $(0,1)$ (Fig. 2b); absolute PASI $\leq 5 / \leq 3 / \leq 2 / \leq 1$ (Fig. 2c)], and improvements in disease severity resulted in improvements in patient-reported QoL (DLQI) (Fig. 3).

To further explore the impact of long-term improvements in skin disease on QoL, we examined the DLQI $(0,1)$ responses among patients achieving PASI $<90$, PASI 90 to $<100$ and PASI 100. Patients who had PASI 100 during Years 1 and 5, 90.6\% and 92.0\%, respectively, also had a DLQI $(0,1)$ response, indicating no impact on QoL throughout the long-term extension period in those patients (Fig. 4). In a previously published analysis of Week 12 data, a similar association was described, with $82.3 \%$ of patients reporting a DLQI $(0,1)$ among PASI 100 responders [46]. While further studies are needed, our long-term data (Fig. 4) suggest maintaining clear skin (PASI 100) over long periods may have an even greater impact on QoL than patients achieving PASI 100 at 12 weeks with ixekizumab [46].

The safety profile in this population (206 patients with 604.3 patient years of exposure) was consistent with previously published integrated safety analyses including up to 
approximately 17,000 patient-years across 13 clinical trials in adult patients with psoriasis $[23,47]$. The SAE IR during year 1 was lower than in subsequent years, which may have been a reflection of the small sample size of this data set. Notably, no deaths and no confirmed cases of anaphylaxis, reactivated tuberculosis or positively adjudicated cases of inflammatory bowel disease were reported. Furthermore, injection site reaction IR and hypersensitivity IR generally decreased with continued exposure, with IRs of 22.9 per 100 patient years and 11.7 per 100 patient years, respectively, during Year 1 , and IRs of 0.8 and 3.3 per 100 patient years, respectively, during Year 5. Few opportunistic infections were reported (IR: 3.6) using Medical Dictionary for Regulatory Activities terms. Incidence rates of cerebro-cardiovascular events, depression and malignancy were similar to those observed in integrated analyses across 13 clinical trials [47].

The data presented here provide additional evidence that inhibition of IL-17A with ixekizumab is beneficial for the long-term management of moderate-to-severe psoriasis. The 5-year data in patients treated with secukinumab, another IL-17A inhibitor, also show high levels of response maintained with a consistent safety profile [32]. Currently, to our knowledge, there are no head-to-head clinical trials between ixekizumab and secukinumab; however, head-to-head analyses of real-world data sources have shown better drug survival over a long time period for ixekizumab [48, 49]. Continued study of real-world data sets is needed to further elucidate the comparative effectiveness of these medicines in more clinically relevant populations that are not restricted to the enrollment criteria of clinical trials [50, 51]. It is not known why there are such differences in effectiveness between these two molecules that target the same cytokine; however, the higher binding affinity of ixekizumab for IL-17A $[49,52]$ and a more consistent dosing regimen over time may contribute to these differences. Further research is needed to bring clarity to this issue.

A notable strength of this study is the use of different methodologies for imputing missing data (i.e., modified nonresponder imputation, observed case and multiple imputation analyses). In long-term studies, missing data often result from discontinuation, and there are a number of reasons patients discontinue a trial, including lack of efficacy, safety issues or nonclinical circumstances [53]. In this study, few patients discontinued because of AEs or lack of efficacy (Tables 2 and 3). To more accurately estimate efficacy over long periods in clinical trials, missing data are imputed using standard methodologies. Observed case analysis reflects efficacy in patients who remain in the study and are treatment compliant but may overestimate efficacy by not accounting for missing data. Analysis by multiple imputation employs modeling to estimate outcomes in patients with missing data but can also overestimate efficacy when there are high numbers of discontinuations [54]. Alternatively, modified nonresponder imputation analysis imputes missing data due to study drug-related events (e.g., inadequate response, AE, lack of efficacy) as non-responders, whereas missing data due to other reasons (e.g., missed visits, lost to follow-up) are included as a predicted value based on statistical modeling of observed data. The modified nonresponder imputation estimation is also considered more conservative and stringent [41]. Ultimately, there is no ideal methodology, and by including multiple methodologies in this report, we attempt to provide a transparent view of our long-term efficacy data and address different clinical questions for clinicians. Importantly, the high levels of efficacy observed in our data are consistent across these methods.

A limitation of this study is the small sample size $(N=206)$, which may restrict the universal applicability of the results. However, an additional randomized controlled study of ixekizumab in psoriasis (UNCOVER-3) [23, 24] has recently been completed, and 5-year data from this study will be made available and should help strengthen conclusions about efficacy and safety.

\section{CONCLUSION}

In conclusion, the results reported here demonstrate patients with moderate-to-severe 
psoriasis receiving the on-label dose regimen of ixekizumab maintain long-lasting efficacy with a consistent safety profile resulting in improved QoL through 5 years of treatment.

\section{ACKNOWLEDGMENTS}

We thank the patients who participated in the studies.

Funding. This study was funded by Eli Lilly and Company. All authors had full access to all of the data in this study and take complete responsibility for the integrity of the data and accuracy of the data analysis. All costs associated with the development of this manuscript including the journal's Rapid Service Fee were funded by Eli Lilly and Company.

Medical Writing Assistance. Medical writing services were provided by Lydia Morris, $\mathrm{PhD}$, of Syneos Health (Morrisville, NC). Support for this assistance was funded by Eli Lilly and Company.

Authorship. All named authors meet the International Committee of Medical Journal Editors criteria for authorship for this article, take responsibility for the integrity of the work as a whole, and have given their approval for this version to be published.

Disclosures. Hany Elmaraghy, Heidi Crane, Himanshu Patel, Russel Burge, Gaia Gallo, David Shrom and Chen-Yen Lin are employees of Eli Lilly and Company and receive salary and own stock from the company. Ann Leung is an employee of Syneos Health, vendor of Eli Lilly and Company. Craig Leonardi has been on an advisory board at and/or been a consultant at and/or received speaker's bureau from and/or is/ was an investigator at the following companies: AbbVie, Actavis, Allergan, Amgen, Boehringer Ingelheim, Celgene, Coherus, Cellceutix, Corrona, Dermira, Eli Lilly and Company, Galderma, Glenmark, Janssen, Leo Pharma, Merck, Novartis, Novella, Pfizer, Sandoz, Sienna, Stiefel, Sun Pharmaceuticals, UCB, Vitae, Wyeth.
Kristian Reich has been on an advisory board at and/or received speaker's bureau from and/or is/ was an investigator at the following companies: AbbVie, Affibody, Almirall, Amgen, Avillion, Biogen, Boehringer Ingelheim, Bristol-Myers Squibb, Celgene, Centocor, Covagen, Dermira, Forward Pharma, Fresenius Medical Care, Galapagos, GlaxoSmithKline, Janssen-Cilag, Kyowa Kirin, Leo, Eli Lilly and Company, Medac, Merck Sharp \& Dohme, Novartis, Miltenyi Biotec, Ocean Pharma, Pfizer, Regeneron, Samsung Bioepis, Sanofi, Sun Pharma, Takeda, UCB, Valeant and Xenoport. Peter Foley has been on an advisory board at and/or been a consultant at and/or received speaker's bureau/honoraria and/or received research and/or travel grants from and/or participated in clinical trials (investigator) of the following companies: AbbVie, Amgen, Astra Zeneca, BMS, Boehringer Ingelheim, Botanix, Celgene, Celtaxsys, CSL, Cutanea, Dermira, Eli Lilly and Company, Galderma, Geneseq, Genetech, GSK, Hexima, Janssen, Leo Pharma, MedImmune, Merck, Novartis, Pfizer, Regeneron Pharmaceuticals Inc, Reistone, Roche, Sanofi, Sun Pharma, UCV Pharma and Valeant. Hideshi Torii has received consulting fees or honoraria from the following companies: AbbVie, Celgene, Eli Lilly and Company, Janssen, Kyowa Hakko Kirin, Mitsubishi Tanabe Pharma and Novartis. Sascha Gerdes has been an advisor to and/or received speakers' honoraria and/or received grants from and/or participated in clinical trials of the following companies: AbbVie, Affibody AB, Akari Therapeutics Plc, Almirall Hermal, Amgen, AnaptysBio, Baxalta, Bayer Health Care, Biogen Idec, Bioskin, Boehringer Ingelheim, Celgene, Centocor, Dermira, Eli Lilly and Company, Foamix, Forward Pharma, Galderma, Hexal AG, Incyte Inc., Isotechnika, Janssen-Cilag, Johnson \& Johnson, Kymab, Leo Pharma, Medac, Merck Serono, Mitsubishi Tanabe, MSD, Novartis, Pfizer, Polichem SA, Regeneron Pharmaceutical, Sandoz Biopharmaceuticals, Sanofi-Aventis, Schering-Plough, Sienna Biopharmaceuticals, Takeda, Teva, UCB Pharma and VBL Therapeutics. Lyn Guenther has been a speaker, consultant, investigator and speaker for Eli Lilly and Company, Leo Pharma, Amgen, Celgene, Merck, Pfizer, AbbVie and Janssen; has been a 
speaker and consultant for Valeant and Tribute; and has been an investigator for Boehringer Ingelheim, Sun Pharmaceuticals and UCB. Melinda Gooderham has been on an advisory board at and/or been a consultant at and/or received speaker's bureau from and/or is/was an investigator at the following companies: AbbVie, Amgen, Akros, Arcutis, Bausch Health, BMS, Boehringer Ingelheim, Celgene, Dermira, Eli Lilly, Galderma, GSK, Janssen, Kyowa Kirin, Medimmune, Merck, Novartis, Pfizer, Regeneron, Sanofi Genzyme and UCB. Laura Ferris has been a consultant and is/was an investigator for AbbVie, Arcutis, BI, Celgene, Dermavant, Eli Lilly and Company, Janssen, Pfizer and UCB. Christopher Griffiths has received honoraria and/or research grants from AbbVie, Almirall, Amgen, BMS, Celgene, Eli Lilly, Galderma, LEO Pharma, Janssen, MSD, Novartis, Pfizer, Sandoz, Stiefel GSK, Sun Pharmaceuticals and UCB Pharma. Kim Papp reports grants and/or personal fees from following companies: AbbVie, Akros, Amgen, Anacor, Arcutis, Astellas, Bausch Health, Baxalta, Boehringer Ingelheim, BristolMyers Squibb, Can-Fite BioPharma, Celgene, Coherus, Dermira, Dow Pharmaceuticals, Eli Lilly and Company, Galderma, Genentech, Gilead, GSK, InflaRx GmbH, Janssen, Kyowa Hakko Kirin, Leo Pharma, Medimmune, Meiji Seika Pharma, Merck (MSD), Merck-Serono, Mitsubishi Pharma, Moberg Pharma, Novartis, Pfizer, PRCL Research, Regeneron, Roche, Sanofi Genzyme, Sun Pharma, Takeda and UCB.

Compliance with Ethics Guidelines. The ethics review boards at each study site provided written approval of the study protocol and informed consent form. The Central Ethics Committee for the UNCOVER-1 and UNCOVER-2 studies in the country of the coordinating investigators (US) studies was the Schulman Associates IRB in Ohio, USA. A list of the ethics committees for countries and study sites for UNCOVER-1 and UNCOVER-2 is presented in ESM Table S3. All procedures performed in studies involving human participants were in accordance with the ethical standards of the institutional and/or national research committee and with the 1964 Helsinki Declaration and its later amendments or comparable ethical standards. Informed consent was obtained from all individual participants included in the study.

Data Availability. The datasets during and/ or analyzed during the current study are available from Eli Lilly on reasonable request. Eli Lilly provides access to all individual participant data collected during the trial, after anonymization, with the exception of pharmacokinetic or genetic data. Data are available to request 6 months after the indication studied has been approved in the US and EU and after primary publication acceptance, whichever is later. No expiration date of data requests is currently set once data are made available. Access is provided after a proposal has been approved by an independent review committee identified for this purpose and after receipt of a signed data sharing agreement. Data and documents, including the study protocol, statistical analysis plan, clinical study report, and blank or annotated case report forms, will be provided in a secure data sharing environment. For details on submitting a request, see the instructions provided at https://www.vivli.org.

Open Access. This article is licensed under a Creative Commons Attribution-NonCommercial 4.0 International License, which permits any non-commercial use, sharing, adaptation, distribution and reproduction in any medium or format, as long as you give appropriate credit to the original author(s) and the source, provide a link to the Creative Commons licence, and indicate if changes were made. The images or other third party material in this article are included in the article's Creative Commons licence, unless indicated otherwise in a credit line to the material. If material is not included in the article's Creative Commons licence and your intended use is not permitted by statutory regulation or exceeds the permitted use, you will need to obtain permission directly from the copyright holder. To view a copy of this licence, visit http://creativecommons.org/licenses/by$\mathrm{nc} / 4.0 /$. 


\section{REFERENCES}

1. Parisi R, Symmons DP, Griffiths CE, Ashcroft DM. Global epidemiology of psoriasis: a systematic review of incidence and prevalence. J Invest Dermatol. 2013;133:377-85.

2. Greaves MW, Weinstein GD. Treatment of psoriasis. N Engl J Med. 1995;332:581-8.

3. World Health Organization. WHO global report on psoriasis. Switzerland: WHO Press; 2016.

4. Kimball AB, Gladman D, Gelfand JM, et al. National Psoriasis Foundation clinical consensus on psoriasis comorbidities and recommendations for screening. J Am Acad Dermatol. 2008;58:1031-42.

5. Lewis-Beck C, Abouzaid S, Xie L, Baser O, Kim E. Analysis of the relationship between psoriasis symptom severity and quality of life, work productivity, and activity impairment among patients with moderate-to-severe psoriasis using structural equation modeling. Patient Prefer Adherence. 2013;7:199-205.

6. Sampogna F, Tabolli S, Abeni D. Living with psoriasis: prevalence of shame, anger, worry, and problems in daily activities and social life. Acta Derm Venereol. 2012;92:299-303.

7. Sterry W, Barker J, Boehncke WH, et al. Biological therapies in the systemic management of psoriasis: International Consensus Conference. Br J Dermatol. 2004;151(Suppl 69):3-17.

8. Ronholt K, Iversen L. Old and new biological therapies for psoriasis. Int J Mol Sci. 2017;18(11):2297.

9. Menter A, Tyring SK, Gordon K, et al. Adalimumab therapy for moderate to severe psoriasis: a randomized, controlled phase III trial. J Am Acad Dermatol. 2008;58(1):106-15.

10. Reich K, Nestle FO, Papp K, et al. Infliximab induction and maintenance therapy for moderateto-severe psoriasis: a phase III, multicentre, doubleblind trial. Lancet. 2005;366(9494):1367-74.

11. Papp KA, Tyring S, Lahfa M, et al. A global phase III randomized controlled trial of etanercept in psoriasis: safety, efficacy, and effect of dose reduction. $\mathrm{Br}$ J Dermatol. 2005;152(6):1304-12.

12. Green LJ, Yamauchi PS, Kircik LH. Comparison of the safety and efficacy of tumor necrosis factor inhibitors and interleukin-17 inhibitors in patients with psoriasis. J Drugs Dermatol. 2019;18(8): 776-88.
13. Kimball AB, Papp KA, Wasfi Y, et al. Long-term efficacy of ustekinumab in patients with moderateto-severe psoriasis treated for up to 5 years in the PHOENIX 1 study. J Eur Acad Dermatol Venereol. 2013;27:1535-45.

14. Langley RG, Lebwohl M, Krueger GG, et al. Longterm efficacy and safety of ustekinumab, with and without dosing adjustment, in patients with moderate-to-severe psoriasis: results from the PHOENIX 2 study through 5 years of follow-up. Br J Dermatol. 2015;172:1371-83.

15. Papp KA, Langley RG, Lebwohl M, et al. Efficacy and safety of ustekinumab, a human interleukin$12 / 23$ monoclonal antibody, in patients with psoriasis: 52-week results from a randomised, doubleblind, placebo-controlled trial (PHOENIX 2). Lancet. 2008;371(9625):1675-84.

16. Blauvelt A, Papp KA, Griffiths CE, et al. Efficacy and safety of guselkumab, an anti-interleukin-23 monoclonal antibody, compared with adalimumab for the continuous treatment of patients with moderate to severe psoriasis: results from the phase III, double-blinded, placebo- and active comparatorcontrolled VOYAGE 1 trial. J Am Acad Dermatol. 2017;76(3):405-17.

17. Reich K, Armstrong AW, Foley P, et al. Efficacy and safety of guselkumab, an anti-interleukin-23 monoclonal antibody, compared with adalimumab for the treatment of patients with moderate to severe psoriasis with randomized withdrawal and retreatment: results from the phase III, double-blind, placebo- and active comparator-controlled VOYAGE 2 trial. J Am Acad Dermatol. 2017;76(3):418-31.

18. Gordon KB, Strober B, Lebwohl M, et al. Efficacy and safety of risankizumab in moderate-to-severe plaque psoriasis (UltIMMa-1 and UltIMMa-2): results from two double-blind, randomised, placebo-controlled and ustekinumab-controlled phase 3 trials. Lancet. 2018;392(10148):650-61.

19. Reich K, Papp KA, Blauvelt A, et al. Tildrakizumab versus placebo or etanercept for chronic plaque psoriasis (reSURFACE 1 and reSURFACE 2): results from two randomised controlled, phase 3 trials. Lancet. 2017;390(10091):276-88.

20. Langley RG, Elewski BE, Lebwohl M, et al. Secukinumab in plaque psoriasis-results of two phase 3 trials. N Engl J Med. 2014;371(4):326-38.

21. Lebwohl M, Strober B, Menter A, et al. Phase 3 studies comparing brodalumab with ustekinumab in psoriasis. N Engl J Med. 2015;373(14):1318-28.

22. Papp KA, Reich K, Paul C, et al. A prospective phase III, randomized, double-blind, placebo-controlled study of brodalumab in patients with moderate-to- 
severe plaque psoriasis. Br J Dermatol. 2016;175(2): 273-86.

23. Gordon KB, Blauvelt A, Papp KA, et al. Phase 3 trials of ixekizumab in moderate-to-severe plaque psoriasis. N Engl J Med. 2016;375:345-56.

24. Griffiths CE, Reich K, Lebwohl M, et al. Comparison of ixekizumab with etanercept or placebo in moderate-to-severe psoriasis (UNCOVER-2 and UNCOVER-3): results from two phase 3 randomised trials. Lancet. 2015;386:541-51.

25. Papp KA, Leonardi CL, Blauvelt A, et al. Ixekizumab treatment for psoriasis: integrated efficacy analysis of three double-blinded, controlled studies (UNCOVER-1, UNCOVER-2, UNCOVER-3). Br J Dermatol. 2018;178:674-81.

26. Abrouk M, Nakamura M, Zhu TH, Farahnik B, Koo J, Bhutani T. The impact of PASI 75 and PASI 90 on quality of life in moderate to severe psoriasis patients. J Dermatolog Treat. 2017;28:488-91.

27. Revicki DA, Willian MK, Menter A, Saurat JH, Harnam N, Kaul M. Relationship between clinical response to therapy and health-related quality of life outcomes in patients with moderate to severe plaque psoriasis. Dermatology. 2008;216:260-70.

28. Stull DE, Griffiths CEM, Gilloteau I, et al. Differential effects of secukinumab vs. ustekinumab for treatment of psoriasis on quality of life, work productivity and activity impairment: a structural equation modelling analysis. $\mathrm{Br} \mathrm{J}$ Dermatol. 2018;178:1297-307.

29. Takeshita J, Callis Duffin K, Shin DB, et al. Patientreported outcomes for psoriasis patients with clear versus almost clear skin in the clinical setting. J Am Acad Dermatol. 2014;71:633-41.

30. Viswanathan HN, Chau D, Milmont CE, et al. Total skin clearance results in improvements in healthrelated quality of life and reduced symptom severity among patients with moderate to severe psoriasis. J Dermatolog Treat. 2015;26:235-9.

31. Zhu B, Edson-Heredia E, Guo J, Maeda-Chubachi T, Shen W, Kimball AB. Itching is a significant problem and a mediator between disease severity and quality of life for patients with psoriasis: results from a randomized controlled trial. Br J Dermatol. 2014;171:1215-9.

32. Bissonnette R, Luger T, Thaci D, et al. Secukinumab demonstrates high sustained efficacy and a favourable safety profile in patients with moderate-tosevere psoriasis through 5 years of treatment (SCULPTURE Extension Study). J Eur Acad Dermatol Venereol. 2018;32:1507-14.
33. Liu L, Lu J, Allan BW, et al. Generation and characterization of ixekizumab, a humanized monoclonal antibody that neutralizes interleukin-17A. J Inflamm Res. 2016;9:39-50.

34. Harper EG, Guo C, Rizzo H, et al. Th17 cytokines stimulate CCL20 expression in keratinocytes in vitro and in vivo: implications for psoriasis pathogenesis. J Invest Dermatol. 2009;129(9): 2175-83.

35. Johansen C, Usher PA, Kjellerup RB, Lundsgaard D, Iversen $\mathrm{L}$, Kragballe $\mathrm{K}$. Characterization of the interleukin-17 isoforms and receptors in lesional psoriatic skin. Br J Dermatol. 2009;160(2):319-24.

36. Krueger JG, Fretzin S, Suarez-Farinas M, et al. IL-17A is essential for cell activation and inflammatory gene circuits in subjects with psoriasis. J Allergy Clin Immunol. 2012;130(1):145-54.e9.

37. Lebwohl MG, Gordon KB, Gallo G, Zhang L, Paul C. Ixekizumab sustains high level of efficacy and favourable safety profile over 4 years in patients with moderate psoriasis: results from UNCOVER-3 study. J Eur Acad Dermatol Venereol. 2020;34(2): 301-9.

38. Zachariae C, Gordon K, Kimball AB, et al. Efficacy and safety of ixekizumab over 4 years of open-label treatment in a phase 2 study in chronic plaque psoriasis. J Am Acad Dermatol. 2018;79(294-301): e6.

39. Fredriksson T, Pettersson U. Severe psoriasis-oral therapy with a new retinoid. Dermatologica. 1978;157(4):238-44.

40. Finlay AY, Khan GK. Dermatology Life Quality Index (DLQI) - a simple practical measure for routine clinical use. Clin Exp Dermatol. 1994;19(3): 210-6.

41. Blauvelt A, Gooderham M, Iversen L, et al. Efficacy and safety of ixekizumab for the treatment of moderate-to-severe plaque psoriasis: results through 108 weeks of a randomized, controlled phase 3 clinical trial (UNCOVER-3). J Am Acad Dermatol. 2017;77:855-62.

42. Leonardi C, Maari C, Philipp S, et al. Maintenance of skin clearance with ixekizumab treatment of psoriasis: three-year results from the UNCOVER-3 study. J Am Acad Dermatol. 2018;79(824-30):e2.

43. Agency EM. ICH E9 (R1) Addendum on estimands and sensitivity analysis in clinical trials to the guideline on statistical principles for clinical trials. 2017.

44. Alcusky M, Lee S, Lau G, et al. Dermatologist and patient preferences in choosing treatments for 
moderate to severe psoriasis. Dermatol Ther (Heidelb). 2017;7:463-83.

45. Torbica A, Fattore G, Ayala F. Eliciting preferences to inform patient-centred policies: the case of psoriasis. Pharmacoeconomics. 2014;32:209-23.

46. Blauvelt A, Griffiths CEM, Lebwohl M, et al. Reaching complete or near-complete resolution of psoriasis: benefit and risk considerations. Br J Dermatol. 2017;177:587-90.

47. Armstrong A, Paul C, Puig L, et al. Safety of ixekizumab treatment for up to 5 years in adult patients with moderate-to-severe psoriasis: results from greater than 17,000 patient-years of exposure. Dermatol Ther (Heidelb). 2020;10(1):133-50.

48. Blauvelt A, Shi N, Burge R, et al. Comparison of realworld treatment patterns among patients with psoriasis prescribed ixekizumab or secukinumab. J Am Acad Dermatol. 2020;82(4):927-35. https:// doi.org/10.1016/j.jaad.2019.11.015.

49. Egeberg A, Bryld LE, Skov L. Drug survival of secukinumab and ixekizumab for moderate-to-severe plaque psoriasis. J Am Acad Dermatol. 2019;82: 173-8.
50. Katkade VB, Sanders KN, Zou KH. Real world data: an opportunity to supplement existing evidence for the use of long-established medicines in health care decision making. J Multidiscip Healthc. 2018;11: 295-304.

51. Malatestinic W, Nordstrom B, Wu JJ, et al. Characteristics and medication use of psoriasis patients who may or may not qualify for randomized controlled trials. J Manag Care Spec Pharm. 2017;23: 370-81.

52. Paul C. Ixekizumab or secukinumab in psoriasis: what difference does it make? $\mathrm{Br} \mathrm{J}$ Dermatol. 2018;178:1003-5.

53. Little RJ, D'Agostino R, Cohen ML, et al. The prevention and treatment of missing data in clinical trials. N Engl J Med. 2012;367(14):1355-60.

54. Langley RGB, Reich K, Papavassilis C, Fox T, Gong $\mathrm{Y}$, Guttner A. Methods for imputing missing efficacy data in clinical trials of biologic psoriasis therapies: implications for interpretations of trial results. J Drugs Dermatol. 2017;16:734-41. 